\title{
Issues and Strategies of Chinese Cultural Overseas Communication under the Background of International Promotion of Chinese
}

\author{
Kehua $\mathrm{Yu}$ \\ Overseas Education College \\ Xiamen University \\ Xiamen, China 361102
}

\begin{abstract}
As Chinese becomes increasingly popular worldwide, the promotion of Chinese language has been shifted from "bringing in" to "going abroad". The promotion and dissemination of Chinese language involves not only language itself but its culture. The spread of Chinese culture remains an important measure to build a harmonious world, enhance the multicultural prosperity, so as to promote Chinese language globally. This paper aims at studying the contents, carriers, methods, patterns and skills of spreading Chinese culture overseas in terms of several existing issues.
\end{abstract}

Keywords-Chinese promotion; cultural communication; communication strategies

\section{The STATUS QUO AND EXISTING IsSUES ON THE DIFFUSION OF CHINESE CULTURE OVERSEAS}

Chinese promotion commenced in the 1950s. During the following fifty years, its development still remained in the stage of "bringing in" domestically. In 2005, the convention of the 1st World Chinese Conference marked the globalization of Chinese promotion. By the end of December, 2015, we have established 500 Confucius Institutes and 1000 Confucius Classrooms in 134 countries, with a total of 1.90 million registered students 1 and over 100 million Chinese learners overseas. Up to date, 61 countries and members of European Union have taken Chinese Teaching into their national educational systems. And some governments have considered Chinese as one of their strategic languages.

However, the international promotion of Chinese involves not only the language itself, but also about the culture. Language acts as the carrier of culture, while culture is a mirror of the language. Therefore, the promotion of Chinese culture overseas turns out to be more and more important and imminent since Chinese learning becomes continuously popular and Chinese international promotion is furthered.

Comprehending and spreading Chinese culture thoroughly and effectively will ensure that the international promotion of Chinese can be launched successfully. The key purpose is to convey the fine Chinese culture and its core

http://www.hanban.edu.cn/article/2015-12/07/content_626351.htm values so that the world can know more about China, China can be easily accepted by the rest of the world so as to eliminate suspicions and misunderstandings between countries, avoid international disputes effectively and make common efforts to build a harmonious world. Therefore, it's a fruitful way towards making Chinese culture available for the world and a key to overcome the barrier in cross-cultural exchanges. Meanwhile, with the rise of China, some factors, such as the changing structure of the world and the intricate international situations, make the world desire to study and know about China. Chinese culture is revived to be the focus concerned by the world and the key to save the world. Besides, the Chinese culture, characterized by a history of 5000 years long, is profound and glamorous and is an important part of world's civilization. Its communication is of advantage to uphold the cultural diversities and prosper the culture of the whole world. Nevertheless, it also meets the requirement of "Global Fever of Chinese Learning" and the international promotion of Chinese.

However, there are some issues existing in the process of Chinese cultural worldwide promotion. For example, the "deficit of Chinese culture" is severe, and the frequent occurrence of aphasia diagnosed from Chinese culture is the objective status quo; moreover, Chinese culture is not powerful enough to go abroad, and a lack of experience becomes one of the causes that inhibit the cultural communication of Chinese overseas. Specifically, the sectional sense of traditional culture is protruding, and monotonous and instilled means of cultural dissemination fail to reach aims as expected. Besides, the contents of culture popularized abroad are simple and plain, which can not spread the core values effectively. What's worse, the focus of spreading culture remains partial because it stresses more on ancient times than the present and attaches more importance to differences rather than similarities. There are other issues, including limited channels of cultural communication, monotonous means and lagging skills, etc.

\section{The COMMUnicAtion StRATEgies OF CHINESE CUlture}

In view of the existing issues and the status quo of Chinese cultural communication overseas, we demand to 
take practical action to meet the requirement of promoting Chinese internationally.

\section{A. Refining the Contents of Cultural Communication, Excavating the Core Values of Chinese Culture and Stressing the Sequence Of Culture Promotion}

Firstly, we should be clear about what kind of culture we are going to spread and what kind of culture can speak for China. Hence we need to excavate the core values of Chinese culture and refine it. Chinese culture has a long history and has formed a culture named Confucianism and Taoism, such as "harmony", "moderation" and "heaven and man combine into one" raised by Confucius and Mencius. Confucianism and Taoism found the spiritual world of Chinese people. Therefore, we should refine the essence of modern culture from Chinese traditional civilizations which also contain the factors shaping the culture of the world. To give it an example, there are the principles of benevolence like "Do not do to others as you would not be done by", "to honor old people as we do our own aged parents, and care for other's children as one's own" or fine merits like "The natural law is that diligence will be rewarded." or "Thrift is a virtue." This cultural spirits are people's common pursuits across the world. On the way of refining core values, we should be sure of the balance of traditional culture and modern civilization, and the primary orientation is that the latter one should achieve a success in creating a distinctive culture so that it can unfold the situations of China in various stages of history. Moreover, the vitality of former one in weeding through the old to bring forth the new can be showed and the glamour of Chinese traditional can be displayed as well. Only if Chinese culture has the attraction can it be appealing in the world.

Chinese culture is so all-embracing that we should not only uphold the core of it, but distinguish the dominant culture from the marginal one, the overall culture from the local one. And Chinese culture is multi-ethnic, which centers Han culture acting as the mainstream. But the culture of minority nationalities lies in the margin. Therefore, we should dismiss the narrow minds of "the ethnic culture being everything" and not give much publicity to the exotic traditional customs of ethnic groups. Otherwise, we ought to attach more importance to Han culture which comes from the Han-majority, and then the world can know what China really is. Naturally, as the culture of ethnic groups is indispensable and it's also the vitality of Chinese culture, it should not be ignored. However, spreading Han culture singularly will discount the abundance of Chinese culture and undermine the prosperity of it. To sum up, importance should be distributed not only to classic culture but common and popular one in the process of Chinese cultural communication. Besides, what we spread should not be particular because it will occur cultural misunderstanding when individual and local culture is popularized.

We should also get along on the sequence between material culture, behavioral culture and cultural perspectives positively. Its sequence as follows: Material culture is at the bottom of it, in the middle is the behavioral culture, and the last one is at the top of which core values are the most important. Material culture remains on the surface, which is vivid, visible, touchable, and enjoyable and can easily arise the interest of cultural workers. The middle one is embodied in communication, and what one says and does represents the culture of his or her country. The last one belongs to minds and spirit. People can only penetrate the essence and nature of their culture when they are under the long-run positive influence of the former two cultures. This is the basic difference between Chinese culture and foreign one and the primary purpose of spreading Chinese culture. Hence we should start with material culture and convey the further meanings of cultural perspectives, then Chinese culture can be spread effectively and its connotation can be displayed. We ought not to mix up its priorities or aim too high. However, we can see material culture and behavioral culture as a bridge that helps people gain an initial understanding, and then cultural perspectives can be popularized smoothly. If we force people to accept them from the very beginning, they may feel brainwashed and antipathy. It will make it more difficult to take in and recognize these ideas.

On the one hand, various demands of people abroad for Chinese culture need to be taken into consideration. In present world, people do not focus on the Sinology of ancient literature and history any more, and they turn to all fields of modern China, including politics, economy, society, etc. On the other hand, different countries have different expectations of Chinese culture because of their distinct interest. For example, Thai and Vietnamese prefer the modern popular Chinese culture, while French, Japanese and people of South Korea tend to traditional one. Besides, the culture recipients are influenced by many factors such as levels of education, artistic refinement and learning motivations and emotion, so their demands for Chinese culture vary greatly. Therefore, further studies of those countries where survey and estimation on the needs of overseas recipients should be done. Only if the content of culture is reasonably sifted and sorted by the demands of audiences can we spread Chinese culture effectively.

\section{B. Reorganizing and Consolidating the Carriers of Cultural Communication, Focusing on Language Teaching, Widening the Channels of That Process}

Up to date, the channels counting on Confucius Institutes seem relatively limited, and its operation is immature and has some shortages. As a result, we should fully explore and take advantage of other carriers, such as native Chinese teachers, culture products (textbooks, films, translations, etc.), Chinese people, overseas Chinese, Chinese communities, overseas Sinologists and other media on the Internet.

Language acts as a carrier of its culture. In the situation of Chinese internationalization, Chinese teaching is a useful way in promoting Chinese culture overseas. First of all, there are over a hundred million Chinese learners overseas, which account for a large population. As a great number of people are learning Chinese currently, it has gradually become a popular language across the world. Secondly, Chinese has its economic advantages. In the face of global economic depression, China maintains its momentum of economic development and possesses a large consumer market. The rest of world is eager to cooperate with China to revive its 
economy and searches for opportunities in increasing employment and enhancing development. No wonder that more and more foreigners learn Chinese. Thirdly, Chinese embodies its own special culture strengths in Chinese characters which belongs to ideography, whilst most of western letters are phonography. They are so different. Chinese character, as one of the three existing ancient scripts in the world, is characterized with traits of being trans-space and time and trans-regional and displays a strong vitality. Chinese characters used to record Chinese culture and history, which also reveal the thoughts and minds of Chinese people. Meanwhile, they are of a graceful shape and have abundant variations just as paintings and poetry. They have created an amazing art, namely, calligraphy. The particularity of Chinese characters makes up the strengths of Chinese culture, which encourages more and more foreigners to learn Chinese.

It's a significant measure to foster overseas Chinese teachers, which can positively settle the problem of lacking Chinese teachers. They are also the spokesmen in their own countries because they play an irreplaceable part in Chinese cultural communication. They are not only familiar with their own language, culture, national conditions, local situations, the people's conditions, educational policies and the characteristics of students' learning methods, but have a great passion and a better knowledge on Chinese and its culture. Therefore, they enable to give free rein to two totally different cultures and promote Chinese culture objectively. Then, the local students will learn it at ease and finally gain cultural identity. These local Chinese teachers is reliable in terms of the promoting process and they offer strengths attached with resources in the fierce competition of global culture. If we Chinese people promote fine culture ourselves, we may be suspected that the action is out of cultural superiority or cultural aggression. However, overseas local Chinese teachers are seen as go-betweens link China and their countries, and they participate in the trend of promoting Chinese culture on their own initiative as third parties. It can fully explain the internal appeal of Chinese culture and prove that its pure purpose is to exchange different cultures, and make Chinese culture merge into the world and achieve cultural prosperity.

Cultural products, offspring of matter and spirit, are the extension of Chinese culture and the important carrier of cultural communication. They are visible, touchable and sensible. Some of them are even audible and enjoyable, which congregate learning, entertainment and sentimental refinement. Under the background of Chinese cultural communication, the creation of fine cultural products can arouse people's interest in learning Chinese so as to spread Chinese culture and drive the development of cultural industry. The environment of non-targeted language is the important limited factor in the promotion of Chinese and Chinese culture. However, cultural products act a decisive role in creating a cultural atmosphere of targeted language, which offsets the environment of non-targeted language. It produces an effect of unconscious acquisition like a classic Chinese poetry describing that "moistens everything silently and softly". As we know, there are many primary carriers in promoting Chinese internationalization, such as supplementary products, daily necessities, Chinese textbooks, other books of Chinese culture, Chinese films and television programs together with animation games, etc.

Chinese people, overseas Chinese and Chinese communities also play an irreplaceable role in that process. They deepen their root into "native culture", but draw upon strengths of other cultures and incorporate fine things, and finally repay and integrate other cultures. Establishing Chinese schools, creating Chinese newspaper and launching cultural activities enriched by Chinese traditions are the means of displaying the spirit and glamour of Chinese culture. Therefore, the world can know more about China so as to recognize it.

At the same time, we need to explore and broaden the channels of emerging cultural communications, such civil institutions as Chinese communities, Chinese restaurants, tea houses and medical centers of traditional Chinese medicine. The cultural activities held in Chinese communities can encourage local people to participate in and enjoy the glamour of Chinese culture, which can have a good social influence on other countries. Moreover, the world-renowned Chinese food not only satisfies the needs of daily life, but reveals the life and thoughts of Chinese people and reflects its profound culture. As the saying goes, "the masses regard food as their Heaven--food is the first necessity of the people". There is no exception in other countries. If we aim to promote culture with distinct purpose, the cultural recipients may reject and keep away from it due to its aggression and mystery. However, food, without any border, is part of life. Only taste and health can evaluate it. Chinese people attach great importance to its collocation and modulation. Chinese cuisines are famous for their excellence in color, flavor and taste, and people can enjoy them in view of its vision, smell and taste. It offer nutrients and health simultaneously, and food therapy is really helpful. Besides, Chinese diet displays people's lifestyles, philosophy of life and aesthetic concepts.

Moreover, Chinese restaurants can be efficient carriers of spreading Chinese culture, which people abroad can go into the core of it. As we all know, tea is originated from China. Nowadays, tea has been the main drink in the world and its culture has been formulated. People cannot live without tea. It quenches thirsty and gives amusement. Drinking tea has the functions of refreshing mind, losing weight and bringing physical fitness and nurturing characters and inspiring one's minds. Tea culture reflects the relationships of tea and life, life and society, together with tea and nature. It also tells the philosophy and wisdom of how Chinese people do in their life. Full play should be given in managing Chinese tea house overseas, which can create a better cultural atmosphere acting as a shortcut for people overseas to experience the life of Chinese style and accept Chinese culture.

Apart from tea culture, traditional Chinese medicine possesses its own special strengths in cultural communication. It covers the shortage of western medicine and has no side-effects and cures complicated diseases. As 
we all know, birth, old age, sickness and death is the common law of life. Traditional Chinese medicine can heal diseases and alleviate pains, moreover, it has a function of health care. It has merged many subjects, such as environmental science, zoology, botany, mineralogy, psychology and ethics. There are three concepts in traditional Chinese medicine, namely, fractal concept, overall concept and dialectical view, which containing the philosophy of Chinese ancients. This is the essence of Chinese culture. Taking advantage of traditional Chinese medicine can be considered as a bridge to spread Chinese culture systematically and comprehensively.

\section{The Localization and Pluralism of Cultural Communication}

Cultural communication is bidirectional and interactive. It requires considering some factors in the targeted country, including national conditions, local situations and people's life conditions. If Chinese stories are told in a way of being easily understood by foreigners, the objectiveness, direction, interest, practice, level and entirety of culture can be fully displayed.

Cultural localization, namely, nationalization or regional basis, to put it specifically, is to make teachers and textbooks localized. Teachers, as the performers of teaching, should localize teaching activities, which means that teachers should proceed from national and local conditions and people's living situations of their country, and teach students in a way that they will be delighted to accept. That enables them to make two different cultures connected. Whilst the localization of textbooks mainly request the contents of textbooks to be local, then social systems, cultural customs, ways of thinking and the traits of native language of the country should be taken into consideration. Teachers should prepare teaching materials and sequence according to the learning features and difficulties of students from different countries. Comparing Chinese with foreign languages in terms of pronunciation, vocabulary, grammar and culture is essential. Dialogue organizing and exercising should embody cultural interaction and communication. Besides, class hours or periods ought to adapt those students.

Pluralism is the purpose of cultural communication. The spread of Chinese civilization should turn singular ways into interactive and pluralistic methods, which can achieve the pluralism and integration of culture. Specifically speaking, teachers should add more in cultural comparison, so Chinese learners can introduce and discuss Chinese culture, their own one and others in the rest of the world in Chinese. Hence they will uphold an objective, inclusive and open attitude towards various cultures, and comprehend various civilizations in the perspective of foreign cultures. In terms of the translations of Chinese classics, we should consider foreign readers' reading habits and cultural psychology. As for the production of Chinese films, Chinese core values should be integrated with popular and alien cultures so that Chinese culture can be spread effectively.

\section{The Industrialization and Marketing-Orientation of Cultural Communication Means}

The cultural means and ranges of communication dominated by government are limited and singular, and they are more officially formal and are likely to be rejected by foreigners. However, non-governmental involvement can not only reduce the economic expenses of government, but make full use of the flexible mechanisms and creativity of cultural communications from these groups and individual organizations, and thus promote the industrialization and marketing-orientation of cultural communication. The means of interpersonal communication are effective ways for the popularization of culture, which is more direct, more vivid and more authentic. It is also important to encourage people from all sectors of society and some private enterprises to invest in shooting Chinese films, developing Chinese animation games and software, compiling supplementary products of Chinese, making great efforts in publishing English versions of Chinese works and supporting the establishment of Chinese schools and Chinese training institutions. Only if we meet the pluralistic and multilevel culture demands of foreigners can cultural industry bring Chinese culture towards the rest of the world.

\section{E. The Modernization and Cyberization of Promoting Skills}

With the development of information age, the emerging cyber-media provides more possibilities in information dissemination and changes people's lifestyles and studying methods completely. It owns greater timeliness, and breaks the limitation of time and space, and shares information in a short time. Many social media like QQ, Wechat, Blog and Facebook, as well as some free online courses like television programs about languages, Podcast, Micro Lesson and MOOC have launched a new revolution of information dissemination. The modern network platforms are capable of conveying fresh and vivid culture in time, and are not longer limited by only texts delivery. And it has been replaced by voice, pictures and videos, which is more real and interactive. The dissemination of Chinese culture dissemination abroad depends on the modern and online spreading means which can help to broaden the range and depth of dissemination. The advanced network technologies are urgently needed to develop multimedia Chinese textbooks, record online Chinese courses and multilingual courses of Chinese culture, establish self-study websites for Chinese learning and create Apps and software for mobile phones, found a virtual museum of exotic culture-experience and make the manmachine chatting come true.

\section{CONCLUSION}

The communication of Chinese culture across the world helps to build a harmonious world, enhances the prosperity of pluralistic culture, promotes the development of the world, and the international popularization of Chinese. In conclusion, the dissemination of Chinese culture overseas should be guided by the demands of overseas cultures. Moreover, the contents, carriers, means, methods and technologies all need to keep pace with the times and improve themselves constantly. 


\section{REFERENCES}

[1] Chen Xiaojing, Bidirectional Cultural Transmission in Intercultural Communication-Discussion on "Aphasia of Chinese Culture", Journal of Jinlin Engineering Normal University, No. 4, 2010.

[2] Hu Xiaoming, How to Tell Chinese Stories-Theories and Practice of "Chinese Culture Reaching Out", Journal of East China Normal University(Humanities and Social Science), No. 5, 2013.

[3] Li Hongliang and Yang Xiaoyu, Chinese International Education and Chinese Cultural Communication in the Times of Globalization, Journal of Xinjiang Vocational University, No. 2, 2013.

[4] Li Yan, Extend Language Communication in Cultural Communication and Deepen Cultural Communication by Language Communication, Applied Linguistics, No. 3, 2014.

[5] Zhang Chunyan, The Communication Channels and the Contents Choosing of the Overseas Communication of Chinese Cultural. Journal of Yunnan Normal University (TCSL) , No. 1, 2014.

[6] Zhang Hui, Design and Reflection of Cultural Activities in Confucius Institutes. Journal of Yunnan Normal University (TCSL), No. 5, 2014. 